\title{
Identifying Leadership Competencies in Medical and Dental Healthcare Professionals in Pakistan
}

\author{
Abbasi $\mathbf{N}^{1 *}$, Çitaku $\mathbf{F}^{2}$, Yasmeen $\mathbf{R}^{1,2}$, Waldrop $\mathbf{M}^{2,3}$, Khan $\mathbf{Y H}^{1,2}$ and \\ Zillioux $\mathrm{D}^{2,3}$ \\ ${ }^{1}$ RIPHAH University, Pakistan \\ ${ }^{2}$ Academy of Leadership Sciences Switzerland, Switzerland \\ ${ }^{3}$ SDW, USA
}

\section{Research Article \\ Volume 6 Issue 1}

Received Date: February 12, 2021

Published Date: March 10, 2021

DOI: $10.23880 /$ oajds-16000290

*Corresponding author: Nabeela Abbasi, HOD, Associate Professor of Oral Biology,

Director Mentoring BDS, Rawal Institute of Health Sciences, Islamabad, Pakistan, Email: nabeelazhm@hotmail.com

\section{Abstract}

To identify and empirically investigate the leadership competencies in medical and dental healthcare professionals in Pakistan. A quantitative, cross-sectional descriptive study with a survey was used to identify the perceived leadership competencies in medical and dental healthcare professionals in Pakistan. 142 medical and dental faculty members and clinicians were selected from four medical and dental colleges and hospitals in Rawalpindi/Islamabad and each participated in an in-person survey. The participants were educators and physicians who held academic positions in medical and dental education. A total of 142 completed the survey out of which 88 (62\%) were women and 54 (38\%) were men. Mean age of women was 38 years and mean age of men was 42 years. A 63-item survey measuring leadership competencies developed by Fadil Citaku, et al. [1], was administered in person to all participants. The five features recognized as leadership proficiencies required for healthcare professions were (1) social responsibility, (2) innovation, (3) self-management, (4) task management and (5) leading others. Cronbach's alpha values of all domains were above 0.7 , indicating scale was reliable and items were stable and internally consistent. Cronbach alpha of the entire questionnaire was 0.961 . The means of the Likert score for all the five major variables (scales) were between 3.57 (honesty and integrity) and 4.30 (personal decision quality). The results of Principal component analysis done on the questionnaire data yielded five competencies of leadership including task management, social responsibility, innovation, self-management, and leading others with high coherence and internal consistency. These identified leadership skills are considered important by all doctors, dentists, males, females, assistant professors and professors alike.

Keywords: Leadership competencies; Healthcare professionals; Doctors; Dentists; Academic performance

Abbreviations: GMC: General Medical Council; TMC: Task Management; SRC: Social Responsibility; SMC: SelfManagement; LOC: Leading Others; IC: Innovation.

\section{Introduction}

Leadership is defined by Fadil Citaku, Vroom and Jago $[1,2]$, "as a process of motivating people to work together collaboratively to accomplish great things". Health care institutions and medical/dental colleges require capable and efficient leaders to deal with the pressures and trials of the modern world [3,4]. Medical and dental educators are involved in various activities like teaching, designing curriculum, assessment, facilitating learning, mentoring, providing a right learning atmosphere and supervising departments and programs. All these activities need some 


\section{Open Access Journal of Dental Sciences}

kind of leadership to achieve the goals [5]. We need effective medical education leaders to produce highly knowledgeable, skilled and socially accountable, empathic doctors. Drucker [6] proposes that competent leaders are those who do the right things and achieve their goals showing results, who are role models for their followers and take responsibility for their actions.

Medical and dental education leaders are challenged by factors like economic constancy, curriculum growth and change, research provision and degree of quality assurance [1]. Ineffective and incompetent leadership will rarely satisfy these demands. Hence, we need to examine several leadership competencies and practices required for fulfilling many responsibilities that are significantly and directly associated with student achievement. Past research has shown that leadership leads to improved productivity and performance [7]. Competent medical and dental leaders need to develop important individual qualities like self-awareness, self-management, continued personal growth, honor, ethics and honesty. They also need to demonstrate important qualities when working with others in collaboration for example building \& maintaining relationships, encouraging involvement of other team members and working within teams [8]. They must effectively manage resources, people and their performance. Furthermore, they have to ensure patient safety by applying knowledge and making wise evidence-based decisions.

The major purpose of this study was to identify and empirically investigate the leadership competencies in medical and dental healthcare professionals in Pakistan. It was designed to replicate, extend and confirm the findings of Citaku, et al. [1].

\section{Leadership competencies in Medical and Dental Education and Profession}

The literature related to medical education leadership is still in its beginning and developing phase. Bland, et al. [9] were among the pioneers to empirically study particular educational leadership competencies for effective universitycommunity partnership in bringing about the change in curriculum. In an ever-changing medical education system, leaders need to have a shared vision with their followers and by good communication and role modeling, they can facilitate change that can be applied both to education and health care services.

Effective leadership is linked with improvement in teaching effectiveness and enhancing educational quality and excellence [10]. Leithwood, et al. [11] discovered that effective school leaders exhibit four main competencies: developing people and teams, setting direction for the future, reforming the organization and supervising the educational program. Bordage, et al. [12] conducted a study to identify skills and qualities of educational directors and they found five significant personal traits which were openmindedness, vision, flexibility, trustworthiness and led by values. McKimm's study results also identified the same qualities but added a few more including self-awareness, selfmanagement, strategic skills, analytical thinking, tolerance and being willing to take risks.

In order to manage the challenges in the new health care systems, specialists and organizations feel the need to improve doctors'/dentists' leadership abilities. As a result, physician leadership programs are developing and growing, appealing to all levels of experience and training. Leadership is an important aspect of physicians' specialized job regardless of field and setting. It is considered necessary for all physicians as mentioned in the General Medical Council's (GMC) publications, Good Medical Practice and Tomorrow's Doctors [8].

Doctors need to develop leadership skills like emotional intelligence, conflict resolution, negotiation, situational sensitivity and style flexibility, strategic planning, stress management, communication skills, team building, solving problems, managing change and acting with integrity. As effective physician leaders, they must have strong morals, ethical values and take responsibility of the public health [13]. Physician leaders have responsibility for training their students and trainees by role modeling, coaching and mentoring [14]. A change in traditional educational methods in healthcare is extremelyimportant to fulfill the requirements of an updated medical service and community expectancy. Academic change cannot be achieved without competent leadership, and the lack of leadership in the past has actually hindered change [15]. It is very important for the leadership to create a favorable educational atmosphere/culture, which not only emphasizes learning but also assessment, analysis and improving education. Hence leadership is critical to bringing about improvement in educational outcomes.

Leadership can be learned, however, identifying, and defining the central competencies of leadership remain elusive. There is an abundance of literature written about leadership, but significant research in area of medical education is lacking. The study done by Citaku, et al. is one of the few which has provided empirical evidence for the most important leadership competencies in medical education [1]. These researchers have developed a leadership competencies model, empirically investigating the core leadership competencies.

This model comprises 63 leadership competencies within five domains: 
1. Social responsibility;

2. Innovation;

3. Self-management;

4. Task Management;

5. Justice orientation.

This empirical model of leadership competencies offers a foundation for developing curricula of training programs to teach and develop leadership competencies in any domain, including medical and dental healthcare professions.

\section{Methods}

Participants a final sample of 142 participants from four medical and dental colleges in Rawalpindi/Islamabad completed the questionnaire survey. The sample of physicians and dentists was achieved by simple random sampling technique. There were 88 women and 54 men, 84 were assistant professors (59\%), 35 associate professors $(24.6 \%)$ and 23 professors (16\%), 79 doctors and 63 dentists. The average age for females was 38 years and for males was 42 years. The mean years of work experience was 13 years.

The professors, associate professors and assistant professors of the above-mentioned institutes were included in the study. They all held either MCPS, FCPS or master degrees. Simple BDS and MBBS with more than five years of work experience were also included.

\section{Survey Procedures}

Survey participants were from four private and public medical colleges, dental colleges and teaching hospitals of Rawalpindi and Islamabad. A 63-item questionnaire measuring leadership competencies designed by Fadil Citaku, et al. [1] was administered in person to all participants. Four institutes were visited, ethical review committee approval was obtained and the questionnaire about leadership was distributed among the faculty members. The data collected was entered in SPSS version 23 for further analysis.

\section{Data Analysis}

SPSS version 23 was used for statistical analysis. Reliability of the survey scores was evaluated by using Cronbach's $\alpha$ and sampling adequacy test by K-M-O test. Descriptive statistics of the survey items was done. Evidence of factorial validity was evaluated by using exploratory factor analysis. Principal component analysis (PCA with 63 items) was done.

One-way ANOVA for 5 extracted factors was conducted. It was performed separately for females and males, doctors and dentists, and finally for assistant professors, associate professors and professors. The mean Likert score and SD (standard deviation) for each item were calculated. This was used to calculate the mean Likert score and SD for each scale by taking the mean of all the items that comprise the scale. Correlation coefficient for each scale and its items was calculated using Pearson's test.

\section{Results}

\section{Descriptive Statistics of the Survey Items}

Descriptive statistics of the items are summarized in Table 1. A large number of respondents rated each item as important (4) or very important (5). For remaining items, the whole scale was used. The calculated means of the items ranged from 3.57 (\#18 honesty and integrity) to 4.30 (\#3 personal decision quality). The SDs are either less than or equal to 1 for five-point items, showing that data points are gathered closely around the mean.

\begin{tabular}{|c|c|c|c|c|}
\hline Items & Minimum & Maximum & Mean & SD \\
\hline Maintain quality & 1 & 5 & 4.19 & 0.88 \\
\hline Succession planning/recruiting & 1 & 5 & 4.18 & 0.76 \\
\hline Personnel decision quality & 1 & 5 & 4.31 & 0.84 \\
\hline Maintaining safety & 1 & 5 & 4.09 & 0.94 \\
\hline Enhancing task knowledge & 1 & 5 & 4.23 & 0.9 \\
\hline Eliminating barriers to performance & 1 & 5 & 4.17 & 0.8 \\
\hline Strategic task management & 1 & 5 & 4.09 & 1 \\
\hline Communication with community & 1 & 5 & 3.81 & 0.99 \\
\hline Providing good example & 1 & 5 & 3.85 & 1.19 \\
\hline
\end{tabular}




\begin{tabular}{|c|c|c|c|c|}
\hline Knowledge of organization justice & 1 & 5 & 3.8 & 1.06 \\
\hline Legal regulations & 1 & 5 & 3.88 & 1.05 \\
\hline Open-door policy & 1 & 5 & 3.66 & 1.1 \\
\hline Explaining decision respect & 1 & 5 & 4.03 & 1.01 \\
\hline Servant leadership & 1 & 5 & 3.74 & 1.1 \\
\hline Distributing rewards fairly & 1 & 5 & 3.98 & 0.97 \\
\hline Responsibility for others & 1 & 5 & 3.8 & 1.03 \\
\hline Financial ethics & 1 & 5 & 4.03 & 0.95 \\
\hline Honesty and integrity & 1 & 5 & 3.57 & 1.47 \\
\hline Being accountable & 1 & 5 & 3.63 & 1.27 \\
\hline Time management & 1 & 5 & 4.18 & 0.97 \\
\hline Goal orientation & 1 & 5 & 4.19 & 0.8 \\
\hline Taking initiatives & 1 & 5 & 4.01 & 1.04 \\
\hline Effort & 1 & 5 & 4.1 & 1.03 \\
\hline Persistence & 1 & 5 & 3.97 & 1.07 \\
\hline Self-control & 1 & 5 & 3.83 & 1.28 \\
\hline Self-tolerance & 1 & 5 & 3.82 & 1.19 \\
\hline Adaptability & 1 & 5 & 3.78 & 1.17 \\
\hline Self-reliance & 1 & 5 & 4.12 & 1.04 \\
\hline Continuous learning & 1 & 5 & 4.06 & 0.97 \\
\hline Seeking feedback & 1 & 5 & 3.95 & 1.04 \\
\hline Communicating with coworkers & 1 & 5 & 3.92 & 1.03 \\
\hline Active listening & 1 & 5 & 3.71 & 1.16 \\
\hline Facilitating discussion & 1 & 5 & 3.81 & 1.05 \\
\hline Developing external contacts & 1 & 5 & 3.9 & 1.03 \\
\hline Psychological knowledge & 1 & 5 & 3.84 & 1.1 \\
\hline Social perceptiveness & 1 & 11 & 3.66 & 1.2 \\
\hline Nurturing relationships & 1 & 5 & 3.66 & 1.15 \\
\hline Taking charge & 1 & 5 & 4.21 & 0.81 \\
\hline Orienting others & 1 & 5 & 3.83 & 0.95 \\
\hline Setting goals for others & 1 & 5 & 4.12 & 0.95 \\
\hline Reinforcing success & 1 & 5 & 4.11 & 0.84 \\
\hline Developing teams & 1 & 5 & 4.2 & 0.82 \\
\hline Knowing principles of learning & 1 & 5 & 4.1 & 0.93 \\
\hline Assessing others & 1 & 5 & 4 & 0.83 \\
\hline Coaching, developing, instructing & 1 & 5 & 4.27 & 0.84 \\
\hline Cooperating & 1 & 5 & 3.76 & 1.23 \\
\hline Resolving conflicts & 1 & 5 & 3.93 & 1.07 \\
\hline
\end{tabular}




\begin{tabular}{|c|c|c|c|c|}
\hline Empowerment & 1 & 5 & 3.95 & 0.98 \\
\hline Political savvy & 1 & 5 & 3.72 & 1.09 \\
\hline Critical thinking & 1 & 5 & 4.23 & 0.9 \\
\hline Creative problem solving & 1 & 5 & 4.28 & 0.95 \\
\hline Identifying problems & 1 & 5 & 4.05 & 0.96 \\
\hline Seeking improvement & 2 & 5 & 4.28 & 0.76 \\
\hline Openness to ideas & 1 & 5 & 3.64 & 1.29 \\
\hline Collaborating & 1 & 5 & 3.74 & 1.11 \\
\hline Perceiving systems & 1 & 5 & 3.92 & 0.93 \\
\hline Evaluating consequences & 1 & 5 & 4.23 & 0.9 \\
\hline Visioning & 1 & 5 & 4.13 & 0.94 \\
\hline Managing the future & 1 & 5 & 4.28 & 0.89 \\
\hline Sensitivity to situations & 1 & 5 & 3.9 & 0.98 \\
\hline Challenging the status quo & 1 & 5 & 3.98 & 1.17 \\
\hline Intelligent risk taking & 1 & 5 & 4.12 & 0.94 \\
\hline Reinforcing change & 1 & 5 & 4.25 & 0.93 \\
\hline
\end{tabular}

Table 1: Descriptive Statistics.

\section{Principal Component Analysis and Reliability}

Numerous explanatory principal component analyses were conducted. It was established that the best solution was five factors as they rated for more than $50 \%$ of the variance, were consistent and logical. The five factors identified as leadership competencies were social responsibility, innovation, self-management, task management and leading others.

After analyzing the values of factor loadings, communalities, and cross-loadings, 20 out of 63 variables were removed based on the following criteria:

Low communalities (i.e. having a value less than 0.3 ), such as LOC6_SP (0.252), SMC9_SR (0.294) and SRC10_FE (0.312) Low factor loading (having a value less than 0.4 ).

Cross loadings having a difference of less than 0.2 . The questions were removed from the following competency domains: four from Task Management, two from Social Responsibility, four from Self-Management, nine from Leading Others and one from Innovation.

To measure the reliability and internal consistency of each factor, Cronbach's coefficient alpha values were calculated for each extracted factor and for the complete data set. A value less than 0.7 is questionable, $0.7-0.8$ is marginal, and $0.8-1$ is acceptable [16]. Cronbach's alpha values of all five domains of competency model were found reliable to be used in our setting. All values of five domains were above
0.7 indicating scale's reliability. A reliable scale is internally consistent and stable overtime.

The results summarized in Table 2 , also show very high reliability of items within each factor. Cronbach's a was 0.78 for Task management, 0.87 for Social Responsibility and Innovation, 0.86 for Self-Management, 0.90 for Leading others and 0.88 for Factor 5 Innovation. All five factors were correlated with each other. The high internal consistency of each factor's items, the overall pattern of factor loadings indicates the coherence of the factors. The items having the highest loadings on Social Responsibility, for example, are honesty and integrity (0.81) and accountability (0.81). All the other loadings on social responsibility were moderate (eg, $>0.40)$ to large $(>0.80)$. Other four factors also showed a same pattern of loadings.

\begin{tabular}{|c|c|c|}
\hline Task Management (TMC) & $4.17 \pm .87$ & 0.78 \\
\hline Social responsibility (SRC) & $3.81 \pm 1.09$ & 0.87 \\
\hline Self-management (SMC) & $4.00 \pm 1.05$ & 0.86 \\
\hline Leading Others (LOC) & $3.93 \pm 1$ & 0.9 \\
\hline Innovation (IC) & $4.07 \pm .97$ & 0.88 \\
\hline Reliability of whole instrument & $3.99 \pm .99$ & 0.85 \\
\hline
\end{tabular}

Table 2: Means and Reliability scores of five domains.

Results indicate that there is agreement between the findings of the original study done by Citaku, et al. and the current study. 


\section{Differences between Men and Women}

Further descriptive analysis of the scales was done according to the gender (Table 3). In the subscale 1, "Task management" the mean scale was $29.06 \pm 3.25$ for males and $29.44 \pm 4.47$ for females. In the subscale 2, "Self-regulation" the mean scale was $45.44 \pm 8.21$ for males and $46.09 \pm$ 9.06 for females. For subscale 3, "Self-management" the mean scale was $43.30 \pm 7.39$ for males and $44.52 \pm 7.72$ for females. For subscale 4, "Leading others", males had mean scale of $73.80 \pm 11.45$ and females had $75.40 \pm 11.76$. The last subscale 5, "Innovation" males had mean scale of $56.22 \pm$ 8.09 and females had $57.63 \pm 8.91$. There were no significant differences for leadership experience between men and women.

\begin{tabular}{|c|c|c|c|c|c|}
\hline & gender & $\mathbf{N}$ & Mean & Std. Deviation & Std. Error Mean \\
\hline \multirow{2}{*}{ TMC total } & Male & 54 & 29.06 & 3.25 & 0.443 \\
\cline { 2 - 6 } & Female & 88 & 29.44 & 4.47 & 0.477 \\
\hline \multirow{3}{*}{ SRC total } & Male & 54 & 45.44 & 8.21 & 1.118 \\
\cline { 2 - 6 } & Female & 88 & 46.09 & 9.06 & 0.966 \\
\hline \multirow{2}{*}{ SMC total } & Male & 54 & 43.3 & 7.39 & 1.006 \\
\cline { 2 - 6 } & Female & 88 & 44.52 & 7.72 & 0.823 \\
\hline \multirow{2}{*}{ LOC total } & Male & 54 & 73.8 & 11.45 & 1.559 \\
\cline { 2 - 6 } & Female & 88 & 75.4 & 11.76 & 1.254 \\
\hline \multirow{2}{*}{ IC total } & Male & 54 & 56.22 & 8.09 & 1.101 \\
\cline { 2 - 6 } & Female & 88 & 57.63 & 8.91 & 0.95 \\
\hline
\end{tabular}

Table 3: Group statistics.

\section{Differences between Doctors and Dentists}

Descriptive analysis of the scales according to the type of healthcare professional was completed revealing the following results (Tables $4 \& 5$ ). In the subscale 1, "Task management" the mean scale was $29.34 \pm 4.12$ for doctors and $29.24 \pm 3.97$ for dentists. In the subscale 2, "Self- regulation" the mean scale was $45.90 \pm 8.75$ for doctors and $45.78 \pm 8.76$ for dentists. For subscale 3 , "Self-management" the mean scale was $44.29 \pm 7.20$ for doctors and $43.76 \pm 8.10$ for dentists. For subscale 4, "Leading others", doctors had mean scale of $75.20 \pm 10.69$ and dentists had $74.27 \pm 12.78$. The last subscale 5, "Innovation" doctors had mean scale of $58.19 \pm 7.17$ and dentists had $55.71 \pm 10.34$.

\begin{tabular}{|c|c|c|c|c|c|}
\hline & type & $\mathbf{N}$ & Mean & Std. Deviation & Std. Error Mean \\
\hline \multirow{3}{*}{ TMC total } & Doctor & 79 & 29.34 & 4.12 & 0.465 \\
\cline { 2 - 6 } & Dentist & 63 & 29.24 & 3.97 & 0.5 \\
\hline \multirow{3}{*}{ SRC total } & Doctor & 79 & 45.9 & 8.75 & 0.985 \\
\cline { 2 - 6 } & Dentist & 63 & 45.78 & 8.76 & 1.104 \\
\hline \multirow{2}{*}{ SMC total } & Doctor & 79 & 44.29 & 7.2 & 0.811 \\
\cline { 2 - 6 } & Dentist & 63 & 43.76 & 8.1 & 1.021 \\
\hline \multirow{3}{*}{ LOC total } & Doctor & 79 & 75.2 & 10.69 & 1.203 \\
\cline { 2 - 6 } & Dentist & 63 & 74.27 & 7.2 .78 & 1.61 \\
\hline \multirow{2}{*}{ IC total } & Doctor & 79 & 58.19 & 7.17 & 0.807 \\
\cline { 2 - 6 } & Dentist & 63 & 55.71 & 10.34 & 1.262 \\
\hline
\end{tabular}

Table 4: Group statistics. 


\begin{tabular}{|c|c|c|c|c|c|}
\hline & & $\mathbf{N}$ & Mean & Std. Deviation & Std. Error \\
\hline \multirow{4}{*}{ TMC total } & Assistant Professor & 84 & 29.32 & 4.01 & 0.438 \\
\hline & Associate Professor & 35 & 29.14 & 4.46 & 0.755 \\
\hline & Professor & 23 & 29.43 & 3.62 & 0.757 \\
\hline & Total & 142 & 29.3 & 4.04 & 0.339 \\
\hline \multirow{4}{*}{ SRC total } & Assistant Professor & 84 & 46.33 & 8.64 & 0.943 \\
\hline & Associate Professor & 35 & 45.11 & 7.91 & 1.338 \\
\hline & Professor & 23 & 45.17 & 10.36 & 2.161 \\
\hline & Total & 142 & 45.85 & 8.72 & 0.732 \\
\hline \multirow{4}{*}{ SMC total } & Assistant Professor & 84 & 44.52 & 7.46 & 0.814 \\
\hline & Associate Professor & 35 & 43.6 & 7.82 & 1.323 \\
\hline & Professor & 23 & 43.04 & 7.91 & 1.651 \\
\hline & Total & 142 & 44.06 & 7.59 & 0.637 \\
\hline \multirow{4}{*}{ LOC total } & Assistant Professor & 84 & 74.96 & 11.9 & 1.299 \\
\hline & Associate Professor & 35 & 75.06 & 10.51 & 1.777 \\
\hline & Professor & 23 & 73.74 & 12.64 & 2.637 \\
\hline & Total & 142 & 74.79 & 11.63 & 0.976 \\
\hline \multirow{4}{*}{ IC total } & Assistant Professor & 84 & 56.61 & 8.76 & 0.956 \\
\hline & Associate Professor & 35 & 57.89 & 8.62 & 1.457 \\
\hline & Professor & 23 & 57.65 & 8.24 & 1.719 \\
\hline & Total & 142 & 57.09 & 8.6 & 0.722 \\
\hline
\end{tabular}

Table 5: Group statistics.

\section{Differences According to Professional Seniority}

Descriptive analysis of the scales relative to professional seniority was completed revealing the following results. In the subscale 1, "Task management" the mean scale was 29.32 \pm 4.01 for Assistant Professors, $29.14 \pm 4.46$ for Associate Professors and 29.43 \pm 3.62 for Professors. In the subscale 2, "Self-regulation" the mean scale was $46.33 \pm 8.64$ for Assistant.

\section{Discussion}

The objective of the current study was to detect and empirically inspect the perceived competencies of leadership in medical and dental healthcare profession and education. Citaku, et al. selected 63 of the most important leadership characteristics for medical education, from an inventory of 107 specific competencies established in a previous study conducted by Wagner, et al. [17]. Citaku leadership competency questionnaire was utilized in the current study to investigate the perceived leadership competencies of healthcare professionals of Pakistan, including only doctors and dentist.
Principal component analysis of the questionnaire data was conducted to acquire five competencies of leadership including Task Management, Social Responsibility, Innovation, Self-Management, and Leading others. Cronbach's alpha reliabilities of the factors were high, showing good coherence and internal consistency. Then differences between men and women, doctors and dentists, assistant professors, associate professors and professors were found for Social Responsibility, Innovation, Task management, Self-management and leading others. There were no significant gender differences on any of the factors, same is true for the different levels of professional seniority. There were no significant differences between doctors and dentists on the five dimensions in the present study. There were considerable differences between doctors and other healthcare professionals in the study done by Citaku, et al. in the domains of innovation, social responsibility and justice orientation. In the present study, only two healthcare professionals, doctors and dentists were included whereas in the Citaku, et al. study, physicians, nurses, midwives and physical therapists were included.

It was identified that all five factors were strongly intercorrelated indicating that they all can accurately evaluate 


\section{Open Access Journal of Dental Sciences}

the same construct of leadership. These results suggest that the five leadership competences represent an articulate and reliable model of leadership in medical education. These five competencies are also integral in the description of leadership provided by Vroom and Jago, "a process of motivating people to work together collaboratively to accomplish great things" in medical education by practicing social responsibility, innovation and justice, and more monotonous activities of self- and task management."

Social responsibility was detected as the most important competency by the doctors and dentists alike, showing empathic concern for the welfare of society. However, in a previous study done by Wagner, et al. [17], dealing with leadership competencies in general, (not specific to healthcare profession) social responsibility was found to be least important. Within the healthcare professions, there is more emphasis placed on collaboration, communication with coworkers and interdisciplinary practice. Citaku, et al. identified a Justice Orientation competency, which was not included in the Wagner, et al. model. It is indicated that maintaining safety, following legal regulations, and monitoring progress, are of utmost importance in the medical profession. Innovation was also identified as a dominant leadership competency in the present study, according to ratings of managing the future, seeking improvement, reinforcing change and creative problem solving.

Another important competency identified through results was leading others, showing high ratings of taking charge, developing teams and coaching. Self-management encourages goal setting and attaining goals in spite of barriers, time management and self-reliance. Task management involves enhancing task knowledge and quality of personal decision-making. These competencies, are all interconnected, theoretically significant and reliable.

The principal component analyses confirmed that medical educators, doctors and dentists do have a common vision of the effective leadership competencies for medical education. They are not fundamentally different regarding the identification of the core competencies of leadership and its importance in the medical and dental profession.

Leadership is faced with challenges of limited resources and high expectations for enhancement in teaching and learning. Hence leadership requires inventive strategies that are built on logical principles and human resources. These competencies are important for health promotion of community and developing leadership in health professionals [1]. If a leader practices high Social Responsibility, Innovation, Self-Management, Task Management and leading others effectively, these competencies will assist him or her to successfully lead others. The current study has various practical implications. First, it has highlighted the importance of leadership in healthcare professions. Second, the Citaku questionnaire tool used in the study provides an in-depth understanding of leadership competencies. Third, the study offers a comprehensive methodology for data analyses that can be replicated in other regions of Pakistan.

Hence there is a need to include leadership in the curriculum of the higher education, which educates and trains future medical and health care professionals. Effective leadership can only be ensured by including it in the curriculum of medical and dental education and by teaching it, thus promoting a shift in the mindset of physicians and educators that leadership skills can be learned. This is how transformation of followers into leaders can be ensured and achieved.

\section{Limitations}

Only a cross-sectional study was conducted due to time constraint. This study only represents doctors and dentists, not including other healthcare professionals like nurses and physiotherapists. The survey reply rate was high (91\%), and it was done in four institutions of Rawalpindi and Islamabad only. This study should be replicated with more representative samples from other major cities of Pakistan to further explore leadership in healthcare professions.

\section{Conclusion}

The current study proves that core competencies of leadership in medical and dental professions can be empirically identified and classified into five factors:

1) Task Management,

2) Social Responsibility,

3) Self-Management,

4) Leading others and

5) Innovation.

These factors are hypothetically logical, relevant and internally consistent in expressing the variance of the data. There are no considerable group differences in the factors, (doctors versus dentists, men versus women or between assistant professors, associate professors and professors). Therefore, the competencies seem to be steady, consistent and logical.

Future research should be conducted in other cities in Pakistan utilizing Citaku's five-factor leadership competency model with bigger representative samples. Future studies could be hypothetically reinforced by using confirmatory factor analyses on a new set of data. In the meantime, I have employed the Citaku's model of leadership competencies to investigate leadership in medical professions education in 
Pakistan. This model can be used by other researchers in future to prove findings of the present study and expand on it.

\section{References}

1. Citaku F, Violato C, Beran T, Donnon T, Hecker K, et al. (2012) Leadership competencies for medical education and healthcare professions: population-based study. BMJ Open 2(2): e000812.

2. Vroom VH, Jago AG (2007) The role of the situation in leadership. Am Psych 62(1): 17-24.

3. Brisbee DC (2007) Looking for leaders: current practices in leadership identification in higher education. Plan Chang 38(1): 77-88.

4. Zaccaro SJ (2007) Traits based perspectives ofleadership. AM Psych 62(1): 6-16.

5. McKimm J, Lieff SJ (2013) Medical education leadership. A Practical Guide for Medical Teachers, $4^{\text {th }}$ (Edn.),.

6. Druker P (1996) Foreword. Not enough generals were killed, In: Hesselbein F, et al. (Eds.), The Leader of Future. San Francisco, Jossey Bass.

7. Bakar MS, Mahmood R (2014) Transformational Versus Transactional: Which Leadership Style Is Preferred In The Public Higher Education Institutions? University Utara Malaysia, 3rd International Conference on Leadership \& Learning in the Asian Century ELLTA.

8. NHS (2010) Medical Leadership Competency Framework: Enhancing Engagement in Medical Leadership-3 ${ }^{\text {rd }}$ (Edn.),. NHS Institute for Innovation and Improvement, Academy of Medical Royal Colleges.
9. Bland CJ, Starnaman S, Hembroff L, Perlstadt H, Henry $\mathrm{R}$, et al. (1999) Leadership behaviors for successful university-community collaborations to change curricula. Acad Med 74(11): 1227-1237.

10. Steinert Y, Nasmith L, McLeod PJ, Conochie I (2003) A teaching scholars program to develop leaders in medical education. Acad Med 78(2): 142-149.

11. Leithwood K, Day C, Sammons P, Harris A, Hopkins D (2009) Successful school leadership: what it is and how it influences pupil learning. Research report 800. National College for School Leadership. University of Nottingham.

12. Bordage G, Foley R, Goldyn S (2000) Skills and attributes of directors of educational programmes, Medical Education 34(3): 206-210.

13. Center for Creative Leadership (2012) A Leadership Competency Model: Describing the Capacity to Lead pp: 1-26.

14. Taylor CA, Taylor C, Stoller JK (2009) The Influence of Mentorship and Role Modeling on Developing Physicianleaders: Views of aspiring and established physicianleaders. Journal of General Internal Medicine 24(10): 1130-1134.

15. Spencer J, Jordan R (2001) Educational outcomes and leadership to meet the needs of modern health care. Quality in Health Care 10(2).

16. Litwin MS (1995) How to measure Survey Reliability and Validity. Sage publications.

17. Wagner S, Bapat A, Bennett M (2011) A Leadership Competency Model. Central Michigan University. 